\title{
THE EFFECT OF METHYL JASMONATE VAPORS ON CONTENT OF PHENOLIC COMPOUNDS IN SEEDLINGS OF COMMON BUCKWHEAT (FAGOPYRUM ESCULENTUM MOENCH)
}

\author{
MARCIN HORBOWICZ1, GRZEGORZ CHRZANOWSKI², \\ DANUTA KOCZKODAJ ${ }^{1}$, JOANNA MiTRUS ${ }^{1}$ \\ Siedlce University, Faculty of Life Sciences \\ ${ }^{1}$ Department of Plant Physiology and Genetics \\ 2 Department of Biochemistry and Molecular Biology \\ Prusa 12, 08-110 Siedlce, Poland \\ e-mail: mhorbowicz@ap.siedlce.pl
}

(Received: February 16, 2010. Accepted: August 25, 2010)

\begin{abstract}
The effect of methyl jasmonate (MJ) vapors on content of phenolic compounds: free phenolic acids, total quercetin, and total phenolics in etiolated buckwheat seedlings were studied. The data presented show that low concentration of $\mathrm{MJ}\left(10^{-8} \mathrm{M}\right)$ had no influence on trans-cinnamic acid (CA), but stimulated the accumulation of chlorogenic acid in hypocotyls and cotyledons of buckwheat seedlings. A moderate dose of $\mathrm{MJ}\left(10^{-6} \mathrm{M}\right)$ did not change the level of chlorogenic acid in the hypocotyls and cotyledons, but CA synthesis was promoted in cotyledons, whereas in hypocotyls no significant effect was found. Highest concentration of $\mathrm{MJ}\left(10^{-4} \mathrm{M}\right)$ caused small decline of CA in hypocotyls, but large stimulation of the acid production in cotyledons was noted. MJ had stimulatory effect on caffeic acid forming, but inhibited synthesis of vanillic acid in hypocotyls and cotyledons. Lowest concentration of $\mathrm{MJ}\left(10^{-8} \mathrm{M}\right)$ elicited accumulation of quercetin glycosides in both studied tissues of buckwheat seedlings, however at higher doses $\left(10^{-6}\right.$ and $\left.10^{-4} \mathrm{M}\right)$ did not affect the flavonol level. The obtained results suggest that nonequivalent influence of methyl jasmonate on the phenolics composition can be a result of various mechanisms of MJ uptake, transforming and/or its translocation in buckwheat hypocotyls and cotyledons. Decline of anthocyanins level in buckwheat hypocotyls caused by MJ cannot be explained by enhanced accumulation of quercetin glycosides or free phenolic acids, but probably by synthesis of other unknown phenolic compounds.
\end{abstract}

KEY WORDS: common buckwheat, methyl jasmonate, trans-cinnamic acid, chlorogenic acid, hypocotyls, cotyledons.

\section{INTRODUCTION}

Phenolic compounds are the main class of secondary metabolites in plants. Several thousand such compounds have been identified in various plant species. The phenolic compounds are important for plant due to their various biological functions including UV protection, pollen tube growth, antimicrobial activity, and insect resistance (Steyn et al. 2002; Winkel-Shirley 2002). Simple phenolic acids such as trans-cinnamic and $p$-coumaric acids are precursors for more complex compounds including flavonoids, tannins, lignins and anthocyanins (Winkel-Shirley 2002).

The common derivatives of trans-cinnamic acid are: caffeic acid (3,4-dihydroxycinnamic acid), ferulic acid (3-methoxy-4-hydroxycinnamic), sinapic acid (3,5-dimethoxy-4-hydroxycinnamic), o-coumaric acid (2-hydroxycinnamic) and $p$-coumaric acid (4-hydroxycinnamic). Chlorogenic acid (5'-caffeoylquinic acid) is the most important cinnamic acid derivative and sometimes is the predominant single phenolic compound in plants (Hahlbrock and Scheel 1989).

Jasmonic acid (JA) and its ester - methyl jasmonate (MJ) are signal molecules and play key roles in plant growth, development and response to stresses such as pathogen attack. MJ is one of the few plant compounds effective as a vapor (Farmer and Ryan 1990). Upon exposure to stress, $\mathrm{MJ}$ is produced and causes activation of defense response in plants, inducing the expression of defensive genes. In the mechanism of defense response in plants phenolic acids and their derivatives play an important role (Creelman and Mullet 1997).

Elicitation is a technique that stimulates plants to accumulate secondary metabolites. Elicitors interact with plant membrane receptors and generate signal compounds, 
which subsequently activate specific genes for highly inducible enzymatic systems involved in secondary metabolite biosynthesis. To elicit abundant flavonoid accumulation in plant-cell cultures MJ has been often used (Fang et al. 1999). Total phenolic compounds content increased after MJ treatments of romaine lettuce (Lactuca sativa L.) and sweet basil (Ocimum basilicum L.) (Kim et al. 2006; Kim et al. 2007). Authors of these studies explain higher accumulation of phenolics due to induction by MJ of phenylalanine ammonia-lyase (PAL) activity. MJ treatment dramatically increased the levels of some secondary metabolites in Nicotiana attenuata leaves but left rutin unchanged (Keinänen et al. 2001). MJ added to Ginkgo biloba cell suspension stimulated phenolic acid production, especially ferulic, chlorogenic and syringic acids (Szewczyk 2008). Additionally, MJ clearly induced the biosynthesis of phenolic acids and flavonoids in root suspension of Panax ginseng cultures (Ali et al. 2007). Generally, MJ as an elicitor enhances biosynthesis of flavonoids and phenolic acids, however in a recently published paper no effect of methyl jasmonate on dicaffeoylquinic and chlorogenic acids was shown in leaf of globe artichoke (Cynara cardunculus L.) (Moglia et al. 2008).

Tissues of buckwheat seedlings accumulate large concentration of various phenolic compounds (Horbowicz et al. 2011). Anthocyanins in plants occur in stems and leaves, and glycosides of quercetin mainly in green tissue. Biosynthesis of light-dependent anthocyanins in hypocotyls of buckwheat seedlings was greatly inhibited by MJ applied as vapors or as water solution, although PAL activity was unchanged (Horbowicz et al. 2008). The results are opposite to the stimulatory effect of MJ, used in lanolin paste, on forming of anthocyanins in other plants (Saniewski et al. 1998; Saniewski et al. 2003; Saniewski et al. 2006).

Since plants synthesize several classes of phenolic compounds via the shikimate pathway we hypothesized that inhibition of anthocyanins biosynthesis in buckwheat hypocotyls by MJ can enhance the level of other phenolics, like phenolic acids. Therefore the aim of the present research was to study the effects of $\mathrm{MJ}$ on particular free phenolic acids content, total phenolics and quercetin in seedlings of common buckwheat (Fagopyrum esculentum Moench).

\section{MATERIAL AND METHODS}

\section{Plant material}

Seedlings of dark-grown buckwheat (Fagopyrum esculentum Moench) cv. Hruszowska were used in these studies. Seeds were germinated between two layers of wet filter paper, which then were rolled and inserted in a 21 beaker containing ca. $200 \mathrm{ml}$ of tap water. Germination process was carried on in darkness at $24 \pm 1^{\circ} \mathrm{C}$. After four days grown in such conditions the seedlings of buckwheat were taken to experiments with MJ treatment (Horbowicz et al. 2008).

The seedlings were exposed to methyl jasmonate vapor in beakers tightly closed with silicon foam, by incubating plants together with strip of filter paper to which had been applied MJ dissolved in ethanol. Ethanol used to prepare the needed solutions was evaporated at ambient tempera- ture during 5 minutes, before inserting the filter paper to the jar. A preliminary experiment showed that the loss of investigated jasmonates during that time is negligible (data not shown). MJ (Sigma-Aldrich) was applied at concentration $10^{-8}, 10^{-6}, 10^{-4} \mathrm{M}$. After $8 \mathrm{~h}$ of pre-incubation in darkness, seedlings samples in beakers were exposed on 3-days light/night photoperiod. Seedlings were then grown in $16 / 8$ $\mathrm{h}$ night/day photoperiod and $65 \pm 5 \%$ of relative humidity. Temperature in growth chamber was maintained at $24 \pm 2^{\circ} \mathrm{C}$ for day and $18 \pm 2^{\circ} \mathrm{C}$ during night period. Light intensity (40 $\mu \mathrm{mol} \cdot \mathrm{m}^{-2} \cdot \mathrm{s}^{-1}$ ) was provided by fluorescent tubes.

\section{Analysis of free phenolic acids}

The analysis of free phenolic acids in buckwheat tissue was carried out by a modified, previously published method (Chrzanowski and Leszczyński 2008). Briefly, freeze-dried plant samples $(100-250 \mathrm{mg})$ were extracted by heating for 1 hour with $80 \%$ methanol contained $1 \%$ (v/v) of acetic acid (Sigma). The mixture was centrifuged (10 $000 \mathrm{~g})$ during $10 \mathrm{minutes,}$ and non-polar substances were removed by double extraction with petroleum ether. Free phenolic acids were extracted with triple extraction with ethyl acetate. Traces of water from pooled acetate layers were removed by adding anhydrous sodium sulphate (Sigma). Then ethyl acetate was evaporated under vacuum, and residue was dissolved in mobile phase mixture (water:methanol, 75:25) containing 1\% (v/v) acetic acid). Phenolic acids were analysed using HPLC method. An isocratic HPLC system was equipped with Photodiode Array Detector (set at 254 and $300 \mathrm{~nm}$ ) and Microsorb MV 100-5 C18 $(250 \times 4.6 \mathrm{~mm})$ column with ChromGurd reversed phase precolumn. Mobile phase flow was $1 \mathrm{~cm}^{3} \cdot \mathrm{min}^{-1}$, and the column temperature was maintained at $27^{\circ} \mathrm{C}$. Phenolic acids were identified by comparison of retention times with appropriate standards purchased from Sigma, and quantified by use standard curves.

\section{Total quercetin analysis}

Determination of quercetin was carried out according to a previously described method (Patil et al. 1995). Briefly, quercetin glycosides were extracted by homogenization of samples in mortar with $60 \%$ ethanol-water solution. Extracted glycosides were subjected to hydrolysis with 1.2 $\mathrm{N} \mathrm{HCl}\left(0.5 \mathrm{~h}\right.$ at temperature $\left.100^{\circ} \mathrm{C}\right)$. Released quercetin was extracted by triplicate vigorous shaking with ethyl acetate. Such obtained quercetin extracts were diluted with mobile phase used for HPLC determination in proportion 1:2 (v/v). To perform the analyses of quercetin, a HPLC apparatus equipped with UV detector set at $370 \mathrm{~nm}$, and a Lichrosorb RP18 $(4 \times 250 \mathrm{~mm}, 10 \mu \mathrm{m})$ column were used. The HPLC was working isocratically and a mobile phase contained mixture of methanol, water $(55: 45, \mathrm{v} / \mathrm{v})$ and $0.2 \%$ ortho-phosphoric acid. The standard curve was prepared for quercetin (Sigma) at concentration range 1 to $10.0 \mu \mathrm{g} \cdot \mathrm{cm}^{-3}$.

\section{Total phenolic analysis}

Total phenolics were determined spectrophotometrically using Folin-Ciocalteau reagent (Sigma). Reagent mixtures were allowed to react at ambient temperature in darkness for 2 hours, and the absorbance of supernatants was measured at $725 \mathrm{~nm}$. Chlorogenic acid was used for a standard curve preparation (Sigma). 
All analyses were carried out in three or four independent replicates, and means were statistically examined by a Newman-Keuls test at $\alpha=0.05$. The different letters in figures and tables indicate significant difference between treatments.

\section{RESULTS AND DISCUSSION}

Figures 1 and 2, and Table 1 show variations in the concentrations of various forms of phenolic acids existing among the different MJ treatments of common buckwheat seedlings. trans-Cinnamic (CA), chlorogenic, caffeic, gallic, para-coumaric, syringic, ferulic, vanilic acids were identified and determined in buckwheat tissues. Among them CA and chlorogenic acid were the quantitatively major free acids. Both represent about $85 \%$ of all the phenolic acids in hypocotyls, and $70 \%$ in cotyledons of the buckwheat seedlings, non-treated with MJ.

It seems that the pathway: $\mathrm{CA} \rightarrow$ chlorogenic, via paracoumaric and caffeic acids, is the predominant free phenolics transformation in buckwheat tissue. Low concentration of MJ vapors did not affect the free CA in buckwheat cotyledons, but its higher doses $\left(10^{-6} \mathrm{M}\right.$ and $\left.10^{-4} \mathrm{M}\right)$ had a clear stimulatory effect on $\mathrm{CA}$ accumulation (Fig. 1). In

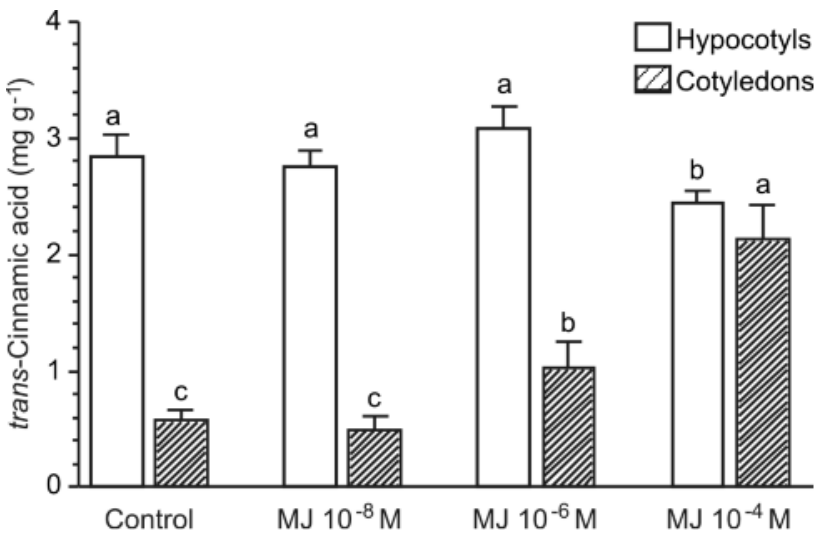

Fig. 1. Effect of methyl jasmonate (MJ) on content of trans-cinnamic acid in hypocotyls and cotyledons of buckwheat seedlings. Significance of difference among results was calculated for cotyledons and hypocotyls separately. Means (bars) marked by the various letters are significantly different at $\alpha=0.05$ according to Newman-Keuls test. case of CA, its level was not significantly different from control when low MJ concentration $\left(10^{-8}\right.$ and $\left.10^{-6} \mathrm{M}\right)$ was used. High concentration of MJ vapors $\left(10^{-4} \mathrm{M}\right)$ caused small, but significant decline of CA content in buckwheat hypocotyls (Fig. 1).

Phenolic acids have some growth regulatory activity in plants, especially roots. Exogenously used trans-cinnamic acid inhibited the growth of the primary root of buckwheat seedlings, while influence of $p$-coumaric acid was not significant. Both investigated acids had no influence on growth of buckwheat hypocotyls and on anthocyanins accumulation in buckwheat seedlings (Horbowicz et al. 2009).

The CA is a substrate for synthesis of both para- and ortho-coumaric acids. In case of ortho-coumaric acid in buckwheat cotyledons there occurs a tendency similar to CA changes under MJ treatment (Table 1). Level of orthocoumaric acid in buckwheat hypocotyls was below of detection limit, and para-coumaric acid in both investigates buckwheat tissues was very low, and not affected by MJ (Table 1).

para-Coumaric acid can be an intermediate in formation of lignin, as well as in production of several flavonoid classes: flavones, flavonols, flavan-3-ols or anthocyanins. Increased content of the para-coumaric acid can be utilized

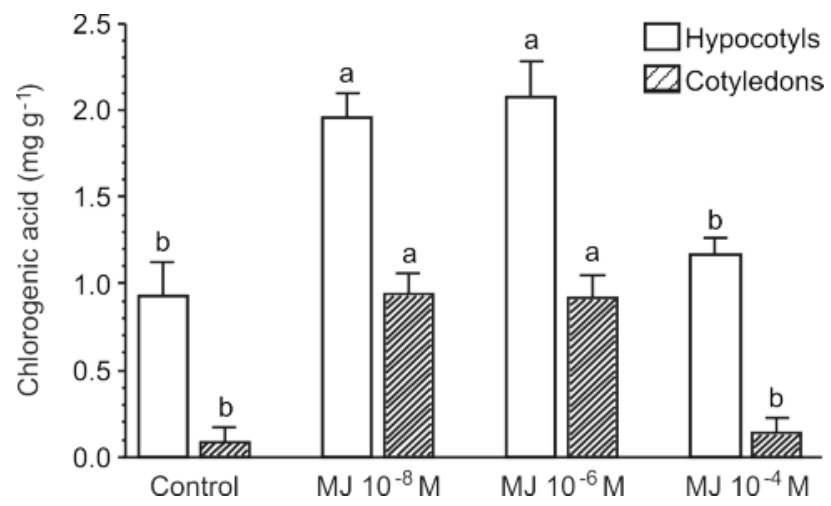

Fig. 2. Effect of methyl jasmonate (MJ) on content of chlorogenic acid in hypocotyls and cotyledons of buckwheat seedlings. Significance of difference among results was calculated for cotyledons and hypocotyls separately. Means (bars) marked by the various letters are significantly different at $\alpha=0.05$ according to Newman-Keuls test.

TABLE 1. Effect of methyl jasmonate (MJ) on content (mg $\cdot \mathrm{g}^{-1}$ dry weight) of minor phenolic acids in buckwheat hypocotyls and cotyledons. Means compared in columns followed by the various letters are significantly different at $\alpha=0.05$ by Newman-Keuls test.

\begin{tabular}{|c|c|c|c|c|c|c|}
\hline Concentration of $\mathrm{MJ}$ vapors & Caffeic acid & Gallic acid & Vanillic acid & Syringic acid & $p$-Coumaric acid & Ferulic acid \\
\hline \multicolumn{7}{|c|}{ Hypocotyls } \\
\hline Control (0) & $0.11 \mathrm{c}$ & $0.14 \mathrm{a}$ & 0.38 & $0.02 \mathrm{~b}$ & $0.02 \mathrm{a}$ & $0.02 \mathrm{a}$ \\
\hline $\mathrm{MJ} 10^{-8} \mathrm{M}$ & $0.16 \mathrm{bc}$ & $0.04 \mathrm{~b}$ & $\operatorname{tr}$ & $0.07 \mathrm{~b}$ & $0.03 \mathrm{a}$ & $0.02 \mathrm{a}$ \\
\hline MJ $10^{-6} \mathrm{M}$ & $0.22 \mathrm{~b}$ & $0.10 \mathrm{a}$ & $\operatorname{tr}$ & $0.05 \mathrm{~b}$ & $0.04 \mathrm{a}$ & $0.05 \mathrm{a}$ \\
\hline $\mathrm{MJ} 10^{-4} \mathrm{M}$ & $0.32 \mathrm{a}$ & $0.10 \mathrm{a}$ & $\operatorname{tr}$ & $0.14 \mathrm{a}$ & $0.03 \mathrm{a}$ & $0.03 \mathrm{a}$ \\
\hline \multicolumn{7}{|c|}{ Cotyledons } \\
\hline Control (0) & $\operatorname{tr}$ & $0.09 \mathrm{~b}$ & 0.03 & $\operatorname{tr}$ & $0.02 \mathrm{a}$ & $0.15 b^{*}$ \\
\hline $\mathrm{MJ} 10^{-8} \mathrm{M}$ & $0.18 \mathrm{~b}$ & $0.10 \mathrm{~b}$ & $\operatorname{tr}$ & $\operatorname{tr}$ & $\operatorname{tr}$ & $0.23 \mathrm{ab}^{*}$ \\
\hline MJ $10^{-6} \mathrm{M}$ & $0.40 \mathrm{a}$ & $0.14 \mathrm{a}$ & $\operatorname{tr}$ & $\operatorname{tr}$ & $0.04 \mathrm{a}$ & $0.36 \mathrm{a}^{*}$ \\
\hline MJ $10^{-4} \mathrm{M}$ & $0.39 \mathrm{a}$ & $0.16 \mathrm{a}$ & $\operatorname{tr}$ & $\operatorname{tr}$ & $0.04 \mathrm{a}$ & $0.19 b^{*}$ \\
\hline
\end{tabular}

$\operatorname{tr}$ - traces; * ortho-coumaric acid 
TABLE 2. Effect of methyl jasmonate (MJ) on total quercetin content in cotyledons and hypocotyls in buckwheat hypocotyls and cotyledons. Means compared vertically followed by the same letters were not significantly different at $\alpha=0.05$ by Newman-Keuls test.

\begin{tabular}{lcc}
\hline \multirow{2}{*}{$\begin{array}{l}\text { Concentration } \\
\text { of MJ vapors }\end{array}$} & Cotyledons & Hypocotyls \\
\cline { 2 - 3 } & Content $\left(\mathrm{mg} \cdot \mathrm{g}^{-1}\right.$ dry weight $)$ \\
\hline Control $(0)$ & $6.35 \mathrm{~b}$ & $5.53 \mathrm{~b}$ \\
MJ $10^{-8} \mathrm{M}$ & $7.11 \mathrm{a}$ & $6.30 \mathrm{a}$ \\
MJ $10^{-6} \mathrm{M}$ & $6.05 \mathrm{~b}$ & $5.23 \mathrm{~b}$ \\
MJ $10^{-4} \mathrm{M}$ & $6.47 \mathrm{~b}$ & $5.99 \mathrm{ab}$ \\
\hline
\end{tabular}

by enhanced synthesis of these compounds. However, the content of total quercetin was not enhanced by $\mathrm{MJ}$ vapors at concentration of $10^{-6}$ and $10^{-4} \mathrm{M}$ (Table 2). MJ applied at $10^{-8} \mathrm{M}$ had only a small stimulatory effect for the synthesis of the total quercetin. On the other hand, MJ clearly stimulated the synthesis of proanthocyanidins (PA) (Horbowicz et al. 2011). Therefore we suppose that $p$-coumaric acid, as $p$-coumaroyl-CoA, is used to synthesize mainly PA, and/or other unknown phenolics.

MJ vapours applied in low concentrations $\left(10^{-8}\right.$ and $\left.10^{-6} \mathrm{M}\right)$ had a stimulatory effect on chlorogenic and caffeic acids contents in buckwheat hypocotyls. High doses of $\mathrm{MJ}\left(10^{-4} \mathrm{M}\right)$ caused the chlorogenic acid content to decline, but the same did not apply for caffeic acid (Fig. 2, Table 1). Phenolic acids, like para-coumaric, caffeic and ferulic, are the main substrates for biosynthesis of lignin, however low level of ferulic acid - intermediate in guiacyl lignin production, on which MJ had no influence, indicate that this pathway is not present in buckwheat hypocotyls and cotyledons. Similar situation was in case of caffeic acid, which occurs in low concentration in buckwheat tissues, and probably is used mainly for synthesis of chlorogenic acid.

The treatment of buckwheat seedlings with MJ caused total decline of vanillic acid (Table 1). For the biosynthesis of vanillic acid, two biosynthetic pathways have been proposed. Because vanillic acid and ferulic acid have identical substitutions on the aromatic ring, vanillic acid could be derived from feruloyl-CoA. However, the content of ferulic acid in buckwheat hypocotyls is very low, and is not present in cotyledons (Table 1). Another possibility of vanillic acid synthesis is from caffeic acid. It needs several steps, the first being the production of isoferulic acid. Subsequently, reactions of methylation, oxidative decarboxylation, and demethylation result in vanillic acid (Funk and Brodelius 1992). Due to relatively high concentration of the caffeic acid, its conversion to vanillic acid is probably possible in buckwheat tissue, although MJ totally inhibited the pathway (Table 1).

It has been shown that gallic acid is synthesized from an early intermediate of the shikimate pathway - 5-dehydroshikimic acid (Werner et al. 1997). Treatment of buckwheat seedlings with MJ slightly stimulated synthesis of gallic acid in cotyledons, but not in hypocotyls (Table 1).

Table 2 summarizes the results of experiments on effect of $\mathrm{MJ}$ on total quercetin content in hypocotyls and cotyledons of common buckwheat seedlings. The total quercetin was determined after acid hydrolysis of its glycosides. Quercetin rutoside (rutin), is the major flavonoid in buckwheat tissue (Couch et al. 1946; Matsui et al. 2008) The results of our studies show that the level of quercetin released from its glycosides was slightly higher in cotyledons than in hypocotyls of common buckwheat. Among applied doses of $\mathrm{MJ}$ only the lowest $\left(10^{-8} \mathrm{M}\right)$ slightly stimulated the biosynthesis of quercetin. Stimulation of flavonoids biosynthesis under the MJ solution was also noted in root suspension of Panax ginseng cultures (Ali et al. 2007), but not in Nicotiana attenuata leaves (Keinänen et al. 2001). Results of our previous studies indicate that MJ declined accumulation of anthocyanins in buckwheat hypocotyls but not in cotyledons, although PAL activity was not inhibited (Horbowicz et al. 2008). Obtained results suggest that the decline of anthocyanins level by MJ probably could enhance formation of other phenolic compounds, like quercetin glycosides, however the results of herewith studies did not show significant stimulation of such synthesis (Table 2).

The results of analyzes of total phenolic compounds in buckwheat tissues are summarized in Table 3. According to the results, MJ generally stimulated accumulation of the total phenolics in buckwheat cotyledons and hypocotyls. It can mean that MJ probably stimulated production of various derivatives of phenolic acids, but in case of their free forms the stimulation is small, and in some acids inhibitory effect was found instead. Stimulation of total phenolic compounds in plant tissues after MJ treatment was found earlier (Ali et al. 2007; Kim et al. 2006; Kim et al. 2007; Szewczyk 2008). Recently it was found that MJ enhances biosynthesis of flavonoids and phenolic acids, but did not affect the contents of dicaffeoylquinic and chlorogenic acids in leaf of globe artichoke (Moglia et al. 2008).

TABLE 3. Effect of methyl jasmonate (MJ) on contents of total phenolic compounds in cotyledons and hypocotyls in buckwheat hypocotyls and cotyledons.. Means compared vertically followed by the same letters are not significantly different at $\alpha=0.05$ by Newman-Keuls test.

\begin{tabular}{lcc}
\hline \multirow{2}{*}{$\begin{array}{l}\text { Concentration } \\
\text { of MJ vapors }\end{array}$} & Hypocotyls & Cotyledons \\
\cline { 2 - 3 } & Content $\left(\mathrm{mg} \cdot \mathrm{g}^{-1}\right.$ dry weight $)$ \\
\hline Control $(0)$ & $21.5 \mathrm{~b}$ & $10.1 \mathrm{~d}$ \\
JA-Me $10^{-8} \mathrm{M}$ & $19.7 \mathrm{~b}$ & $16.3 \mathrm{~b}$ \\
$\mathrm{JA}-\mathrm{Me} 10^{-6} \mathrm{M}$ & $22.1 \mathrm{~b}$ & $19.2 \mathrm{a}$ \\
$\mathrm{JA}-\mathrm{Me} 10^{-4} \mathrm{M}$ & $25.0 \mathrm{a}$ & $13.9 \mathrm{c}$ \\
\hline
\end{tabular}

\section{CONCLUSIONS}

In conclusion, this study has demonstrated that the effect of MJ on phenolic acids in buckwheat seedlings depended on the concentration of used MJ vapors, and analysed tissue. The data presented in this study show that low concentration of $\mathrm{MJ}\left(10^{-8} \mathrm{M}\right)$ had no influence on trans-cinnamic acid (CA), but stimulated accumulation of chlorogenic acid in hypocotyls and cotyledons of buckwheat seedlings. Under moderate dose of $\mathrm{MJ}\left(10^{-6} \mathrm{M}\right)$ the hypocotyls and cotyledons formed similar (to $\mathrm{MJ}$ at $10^{-8} \mathrm{M}$ ) levels of chlorogenic acid, and CA synthesis in cotyledons was promoted, whereas in hypocotyls no significant effect was found. MJ vapors at highest concentration $\left(10^{-4} \mathrm{M}\right)$ caused small decline of CA in hypocotyls, but large stimulation of the acid production was noted in cotyledons.

MJ caused stimulation of caffeic acid synthesis, and total inhibition of vanillic acid synthesis in hypocotyls and cotyledons of buckwheat seedlings. Small concentration of 
MJ vapors $\left(10^{-8} \mathrm{M}\right)$ caused enhanced accumulation of quercetin and its glycosides in both studied tissues of buckwheat seedlings, however MJ at higher doses $\left(10^{-6}\right.$ and $\left.10^{-4} \mathrm{M}\right)$ did not affect the flavonol level.

The obtained results suggest that nonequivalent influence of methyl jasmonate vapors on the phenolics composition can be a result of various mechanisms of MJ uptake, transforming and/or its translocation in buckwheat hypocotyls and cotyledons. The decline of anthocyanins level in buckwheat hypocotyls caused by MJ cannot be explained by enhanced accumulation of quercetin glycosides or free phenolic acids, but probably by the synthesis of other unknown phenolic compounds.

\section{LITERATURE CITED}

ALI M.B., HAHN E.-J., PAEK K.-Y. 2007. Methyl jasmonate and salicylic acid induced oxidative stress and accumulation of phenolics in Panax ginseng bioreactor root suspension cultures. Molecules 12: 607-621.

CHRZANOWSKI G., LESZCZYŃSKI B. 2008. Induced accumulation of phenolic acids in winter triticale (Triticosecale Wittm.) under insects feeding. Herba Pol. 54: 33-40.

COUCH J.F., NAGHSKI J., KREWSON C.F. 1946. Buckwheat as a source of rutin. Science 103: 197-198.

CREELMAN R.A., MULLET J.E. 1997. Biosynthesis and action of jasmonates in plants. Ann. Rev. Plant Physiol. Plant Mol. Biol. 48: 355-381.

FANG Y., SMITH M.A.L., PÉPIN M.-F. 1999. The effects of exogenous methyl jasmonate in elicited anthocyanin-producing cell cultures of ohelo (Vaccinium pahalae). In Vitro Cell. Dev. Biol. Plant 35: 106-113.

FARMER E.E., RYAN C.A. 1990. Interplant communication: airborne methyl jasmonate induces synthesis of proteinase inhibitors in plant leaves. Proc. Natl. Acad. Sci. USA 87: 7713-7716.

FUNK C., BRODELIUS P.E. 1992. Phenylpropanoid metabolism in suspension cultures of Vanilla planifolia Andr. IV. Induction of vanillic acid formation. Plant Physiol. 9: 256-262.

HAHLBROCK K., SCHEEL D. 1989. Physiology and molecular biology of phenylpropanoid metabolism. Ann. Rev. Plant Physiol. Plant Mol. Biol. 40: 347-369.

HORBOWICZ M., GRZESIUK A., DEBSKI H., KOCZKODAJ D., SANIEWSKI M. 2008. Methyl jasmonate inhibits anthocyanins synthesis in seedlings of common buckwheat (Fagopyrum esculentum Moench). Acta Biol. Crac., Ser. Bot. 50: 71-78.

HORBOWICZ M., MIODUSZEWSKA H., KOCZKODAJ D., SANIEWSKI M. 2009. The effect of methyl jasmonate and phenolic acids on growth of seedlings and accumulation of anthocyanins in common buckwheat (Fagopyrum esculentum Moench). Acta Agrobot. 62: 49-56.
HORBOWICZ M., WICZKOWSKI W., KOCZKODAJ D., SANIEWSKI M. 2011. Effects of methyl jasmonate on accumulation of flavonoids in seedlings of common buckwheat (Fagopyrum esculentum Moench). Acta Biol. Hungar. (in press)

KEINÄNEN M., OLDHAM N.J., BALDWIN I.T. 2001. Rapid HPLC screening of jasmonate induced increases in tobacco alkaloids, phenolics, and diterpene glycosides in Nicotiana attenuate. J. Agric. Food Chem. 49: 3553-3558.

KIM H.J., CHEN F., WANG X., RAJAPAKSE N.C. 2006. Effect of methyl jasmonate on secondary metabolites of sweet basil (Ocimum basilicum L.). J. Agric. Food Chem. 54: 2327-2332.

KIM H.J., FONSECA J.M., CHOI J.H., KUBOTA C. 2007. Effect of methyl jasmonate on phenolic compounds and carotenoids of romaine lettuce (Lactuca sativa L.). J. Agric. Food Chem. 55: 10366-10372.

MATSUI K., EGUCHI K., TETSUKA T. 2008. A novel gene that diverts the anthocyanin biosynthetic pathway towards the production of proanthocyanidins in common buckwheat (Fagopyrum esculentum). Breed. Sci. 58: 143-148.

MOGLIA A., LANTERI S., DOMINO C., ACQUADRO A., DE VOS R., BEEKWILDER J. 2008. Stress-induced biosynthesis of dicaffeoylquinic acids in globe artichoke. J. Agric. Food Chem. 56: 8641-8649.

PATIL B.S., PIKE L.M., YOO K.S. 1995. Variation in the quercetin content in different colored onions (Allium cepa L.). J. Am. Soc. Hort. Sci. 120: 909-913.

SANIEWSKI M., MISZCZAK A., KAWA-MISZCZAK L., WEGRZYNOWICZ-LESIAK E., MIYAMOTO K., UEDA J. 1998. Effects of methyl jasmonate on anthocyanin accumulation, ethylene production, and $\mathrm{CO}_{2}$ evolution in uncooled and cooled tulip bulbs. J. Plant Growth Regul. 17: 33-37.

SANIEWSKI A., HORBOWICZ M., PUCHALSKI J. 2006. Induction of anthocyanins accumulation by methyl jasmonate in shoots of Crassula multicava Lam. Acta Agrobot. 59: 43-50.

SANIEWSKI M., HORBOWICZ M., PUCHALSKI J., UEDA J. 2003. Methyl jasmonate stimulates the formation and the accumulation of anthocyanin in Kalanchoe blossfeldiana. Acta Physiol. Plant. 25: 143-149.

STEYN W.J., WAND S.J.E., HOLCROFT D.M., JACOBS G. 2002. Anthocyanins in vegetative tissues: a proposed unified function in photoprotection. New Phytol. 155: 349-361.

SZEWCZYK A. 2008. Wpływ elicytacji jasmonianem metylu na akumulację kwasów fenolowych w kulturach zawiesinowych Ginkgo biloba L. (Effects of methyl jasmonate elicitation on the accumulation of phenolic acids in cell culture of Ginkgo biloba L.). Zesz. Problem. Post. Nauk Roln. 524: 419-423.

WERNER I., BACHER A., EISENREICH W. 1997. Retrobiosynthetic NMR studies with $13 \mathrm{C}$-labeled glucose. Formation of gallic acid in plants and fungi. J. Biol. Chem. 272: 25474-25482 .

WINKEL-SHIRLEY B. 2002. Biosynthesis of flavonoids and effects of stress. Curr. Opin. Plant Biol. 5: 218-223. 